\title{
Hypothermia during Surgical Treatment of Type A Aortic Dissection: A 16 Years' Experience
}

\author{
Francesco Macrina, Maria Cristina Acconcia, Luigi Tritapepe $\mathbb{D}^{D}$, Mizar D’abramo, \\ Wael Saade $\mathbb{B}$, Alessandra Capelli, and Fabio Miraldi
}

\begin{abstract}
Department of Cardiovascular, Respiratory, Nephrologic, Anesthesiologic, and Geriatric Sciences, UOD Anesthesia and Intensive Care in Cardiac Surgery, Sapienza University of Rome, Rome, Italy
\end{abstract}

Correspondence should be addressed to Wael Saade; wael.saade@uniroma1.it

Received 15 April 2019; Revised 2 September 2019; Accepted 15 October 2019; Published 25 January 2020

Academic Editor: Antonio Bozzani

Copyright (c) 2020 Francesco Macrina et al. This is an open access article distributed under the Creative Commons Attribution License, which permits unrestricted use, distribution, and reproduction in any medium, provided the original work is properly cited.

\begin{abstract}
Acute aortic dissection (AAD) is among the most challenging cases for surgical treatment and requires procedural expertise for its safe conduct. Aortic surgery has undergone several changes over the last years, especially concerning cerebral protection. The brilliant results obtained with the aid of selective anterograde cerebral perfusion led to a progressive increase of circulatory arrest temperature, with the rise of safe time along with a reduction of the extracorporeal circulation time and hypothermia-related side effects. However, there is still no definitive consensus concerning the optimal range of temperature to be used during circulatory arrest. Objectives. This is a retrospective observational study, and we examined 16-year trends in the presentation, diagnosis, hospital outcome and treatment of A AAD type. In our Cardiac Surgery Unit in Policlinico Umberto I of Rome, our analysis focused on patients, who received ACP during aortic surgery and we analyzed the differences between two distinct groups based on the lowest temperature reached during $\mathrm{CPB}$ conduction: Lower Temperature Group $(\mathrm{LT})\left(T<24^{\circ} \mathrm{C}\right)$ versus Higher Temperature Group $(\mathrm{HT})\left(T \geq 24^{\circ} \mathrm{C}\right)$ arrest circulation temperature. Methods. Data from 241 patients enrolled between August 2002 and March 2018 were analyzed. Patients were divided according to the lowest temperature reached into 2 groups: Lower Temperature group (LT) (94 patients) and Higher Temperature Group (HT) (147 patients). Results. Our results showed a significant reduction of in-hospital mortality and in-hospital results in patients with higher CPB temperature. The global incidence of complications was statistically reduced in HT group: we found a statistical significant reduction of intestinal ischemia, and a similar trend also for other complications analyzed, such as infections. Since the two groups were similar for type of surgical procedures, we considered these differences depending on the lower temperature value reached, according to the current literature. Conclusions. We found a significantly higher mortality in patients with lower temperature during $\mathrm{CPB}$ and a global reduction of complications and in particular a significant reduction of intestinal ischemia in patients with higher temperature during $\mathrm{CPB}$. We found a similar trend in other fields of investigations, so we can conclude that circulatory arrest performed at temperature $\geq 24^{\circ} \mathrm{C}$ nasopharyngeal temperature associated with $\mathrm{ACP}$ is a safe strategy for aortic surgery for AAD.
\end{abstract}

\section{Background}

Aortic dissection, is among the most challenging cases for surgical treatment and requires procedural expertise for its safe conduct. Aortic surgery has undergone several changes over the last years, especially concerning cerebral protection. Three main strategies for cerebral protection have been developed and studied. These are deep hypothermic circulatory arrest (DHCA), retrograde cerebral perfusion (RCP) and antegrade cerebral perfusion (ACP).
The recent trend among cardiothoracic surgeons is to avoid DHCA, where hypothermia was the only protection for the whole body, in favor of adjunctive perfusion techniques, RCP and ACP. This led to a different approach regarding circulatory arrest temperature value. According to an expert Consensus [1], hypothermia has been classified into four categories.

1.1. Absolute Hypothermia. Absolute hypothermia has been defined as a temperature below or equal to $14^{\circ} \mathrm{C}$. At such 


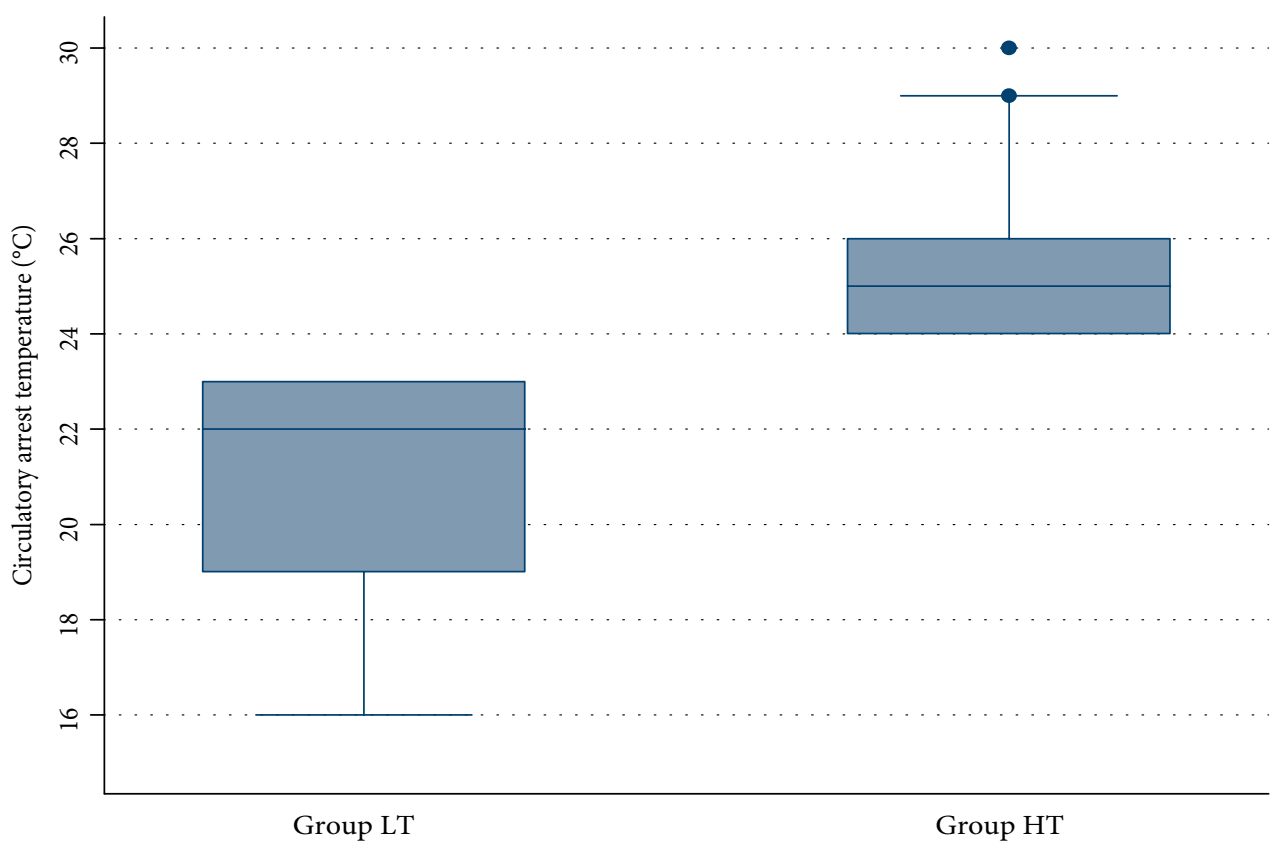

FIgURE 1: Box plot showing distribution of temperature over our population.

temperature, between $14 \%$ and $22 \%$ of pts do not reach electroencephalography (EEG) electric silence. Safe time is estimated to be $30-40$ minutes. This temperature range has now been abandoned due to the negative consequences of longer cooling and rewarming time. The use of absolute hypothermia did not provide significant advantages, since the decrease in metabolism is small in relation to deep hypothermia (DH) [2] and in addition to all the problems associated with $\mathrm{DH}$, it should be added that it greatly lengthens the cardiopulmonary bypass $(\mathrm{CPB})$ time, causes a loss of brain self-regulation and promotes immunosuppression.

1.2. Deep Hypothermia. Deep hypothermia (DH) has been defined as a temperature between $14.1^{\circ} \mathrm{C}$ and $20^{\circ} \mathrm{C}$. At $20^{\circ} \mathrm{C}, 75-88 \%$ of patients do not reach EEG electric silence. Estimated circulatory arrest safe time is $20-30$ minutes.

1.3. Moderate Hypothermia. Moderate hypothermia (MH) has been defined as a temperature between $20.1^{\circ} \mathrm{C}$ and $28^{\circ} \mathrm{C}$. At $28^{\circ} \mathrm{C}, 99-100 \%$ of patients do not reach EEG electric silence.

Circulatory arrest safe time is estimated to be $10-20$ minutes.

Cerebral activity rises by $37 \%$ between $20^{\circ} \mathrm{C}$ and $25^{\circ} \mathrm{C}$.

1.4. Mild Hypothermia. Mild hypothermia (Over $\left.28^{\circ} \mathrm{C}\right)(\mathrm{mH})$ was not sufficient to get EEG electric silence in $100 \%$ of pts, and estimated safe time is only 10 minutes. One study found that in order to achieve cerebral electrical inactivity in $>95 \%$ of patients it was needed to lower the temperature to $12.7^{\circ} \mathrm{C}$ [3].

The brilliant results obtained with the aid of selective anterograde cerebral perfusion, led to a progressive reduction of the circulatory arrest temperature, with the rise of safe time along with a reduction of the $\mathrm{CPB}$ time, as a consequence of the reduction of time needed to cool and rewarm the patient [4] and of the hypothermia-related side effects.
However, there is still no definitive consensus concerning the optimal range of temperature to be used during circulatory arrest [5-9].

This study examined 16-year trends in the presentation, diagnosis, hospital outcome and treatment of type A AAD in our Cardiac Surgery Unit at Policlinico Umberto I of Rome. We focused our analysis on the differences between two strategies on $\mathrm{CPB}$ temperature conduction: lower $\left(T<24^{\circ} \mathrm{C}\right)$ versus higher $\left(T \geq 24^{\circ} \mathrm{C}\right)$ circulatory arrest temperature (Figure 1$)$. ACP was performed in all patients.

\section{Methods}

2.1. Patient Selection. Data were collected on a population of 241 patients who presented with AAD from August 2002 through March 2018 and underwent surgery for type A Aortic dissection at Policlinico Umberto I Cardiac Surgery Department with ACP strategy. Patients were divided into 2 groups reflecting the differences in lowest temperature value on $\mathrm{CPB}$ during this 16-years observation.

Data on patient demographic characteristics, presenting history, physical examination, imaging studies, management, and hospital outcomes were collected from our institutional database.

All patients were invasively monitored during surgery with Trans-Esophageal Echography (TEE) and at least one arterial line and a large peripheral venous line. One central venous access was used routinely, almost always represented by a multi-lumen jugular vein catheter. Both bladder and nasopharyngeal temperatures were monitored. Neurologic monitoring was accomplished by (Near Infrared Cerebral Saturation (INVOS $^{\mathrm{m}}$ 5100C Cerebral/Somatic Oximeter, Medtronic, Minneapolis, MN). 
Anesthesia protocol was maintained unchanged during the study and consisted of intravenous anesthesia technique based on propofol TCI $(1.5 \mathrm{mg} / \mathrm{ml})$ supplemented by continuous infusion of Sufentanil $(0.35-0.5 \mathrm{mcg} / \mathrm{kg} / \mathrm{hr})$ and refracted boluses of muscle relaxants with $\mathrm{BIS}^{\mathrm{Tm}}$ control of adequate hypnosis level.

The rewarming process had not undergone into any modification over the years. First of all, adequate duration was maintained to allow homogeneous brain warming (about 30 minutes) considering that the brain receives about $15 \%$ of cardiac output, with the maintenance of a thermal gradient between the water of the thermo-circulator and venous blood of the circuit below $\left(10^{\circ} \mathrm{C}\right)$. For better maintenance of cerebral self-regulation and optimization of cellular enzymatic activity alpha-stat strategy is used. Finally, it must not be forgotten that the temperature rise with respect to the time unit $\left({ }^{\circ} \mathrm{C} /\right.$ minutes) is also a function of the pump flow, which in turn is also a function of the surgical needs as well as of the patient's metabolic needs.

We considered as adverse outcomes: perioperative mortality; neurological deficits; focal deficits; acute kidney injury requiring dialysis, intestinal ischemia; need for post-operative tracheostomy and peri-operative infections. "Neurological deficits" were defined as both temporary and permanent significant deficits, discovered during the post-operative period. "Focal deficits" consisted of a set of symptoms or signs in which causation could be localized to an anatomic site in the central nervous system [10]. "Acute kidney injury (AKI) requiring dialysis" was defined as a loss of kidney function or terminal kidney failure according to KIDGO criteria.

"Intestinal ischemia" was defined as a condition related to a reduction of splanchnic hematic flow, that could be caused by heart failure and aggravated by inotrope use and/or vasopressors and by atherosclerotic plaques [11]. "Infections" were suspected when as at least a single white cell value above $12.000 \mathrm{cell} / \mathrm{mm}^{3}$ was recorded along with a temperature above $38^{\circ} \mathrm{C}$ and an increased value of PCT during the post-operative period, criteria believed to have a high specificity for infections $[12,13]$.

Data were analyzed retrospectively to investigate whether a statistical association existed between the previously considered adverse outcomes and the temperature ranges. Group data were analyzed for historical trends in demographic characteristics, presentation, evaluation, management, and hospital outcomes.

2.2. Statistical Analysis. Categorical data were presented as absolute frequencies and percent values. Quantitative measurements were expressed as mean \pm SD and were checked for testing the normality of distribution (Shapiro-Wilk test) either in the overall patients as well as in the two groups of patients separately considered. In addition, Levene's test was used for testing the homogeneity of variance between groups. Due to non-normality of data and/or dishomogeneity of variance for some variables, the two groups of patients (Group LT: arrest circulation temperature $<24^{\circ} \mathrm{C}$; Group HT: higher arrest temperature $\geq 24$ ) were compared by Mann-Whitney test for the quantitative variables. The categorical variables were compared by Fisher's exact probability test (in case of two by-two contingency tables) or chi-square test. Bonferroni's correction was applied in case of multiple comparisons to control the experiment wise Type I error probability. $\mathrm{H}_{1}$ was postulated bidirectional for all the analyses. A $p$ value of $<0.05$ was considered statistically significant. Statistical analysis was performed using the STATA Statistical Software: Release 10, College Station, TX: StataCorp LP.

\section{Results}

Across the 16-year period, we did not find relevant differences regarding most of patients' demographics and risks factors, apart from a greater incidence of Marfan syndrome in group HT. We witnessed a difference on symptoms at presentation, with a greater incidence of chest pain and pulse deficits in group HT, a lower incidence of syncope at presentation (Table 1).

In fact, in the group LT the temperature reached lower values $\left(21.1^{\circ} \mathrm{C} \pm 2.2^{\circ} \mathrm{C}\right)$ in respect of the group $\mathrm{HT}\left(25.3^{\circ} \mathrm{C} \pm 1.3^{\circ} \mathrm{C}\right)$.

There was no statistical difference between the CPB time over the two groups, but there was a significant difference in the circulatory arrest time, as showed in Table 2 (Figure 2). No significant difference was found regarding the surgical strategy adopted between the two groups (Table 2).

The 30 -day mortality rate was $34 \%$ in the group LT (32/94) and $21.4 \%$ I the group HT $(32 / 147)(p=0.038)$ (Table 3). In hospital results showed a significant difference between the 2 groups $(p=0.019)$ (Table 3$)$. More specifically, at discharge $58(61.7 \%)$ patients in the group LT and $113(76.9 \%)$ in the group HT were alive. On the other hand, death of all causes occurred in 36 patients in group LT and in 35 patients in group HT. Multiple comparisons demonstrated that despite a similar intraoperative mortality ( $p=\mathrm{NS}$ ), a significant greater mortality was observed in the postoperative course in group LT $(p<0.03)$ (Table 3).

We analysed the complications observed during the in-hospital stay, and our results are listed in Table 3.

\section{Discussion}

Acute aortic dissection is a life-threatening condition, and different techniques have been developed to diminish the mortality and the complications of the surgical procedure.

In our analysis, we investigated the optimal temperature range during circulatory arrest dividing our patients in two groups, group LT and group HT: group LT with a deeper hypothermia strategy $\left(T<24^{\circ} \mathrm{C}\right)$ and group HT with higher hypothermia strategy $\left(T \geq 24^{\circ} \mathrm{C}\right)$. Choosing this temperature as a cut-off for the analysis in this study was fundamentally based on our center experience regarding the temperature to reach during hypothermia that changed over the years, with a progressive approach to higher temperature supported both by the literature and our results $[14,15]$.

Despite the cardiopulmonary times were not significantly different between the 2 groups, HCA time was significantly longer in the lower temperature (LT) group without any significant difference regarding the surgical strategy performed. 
TABLE 1: Demographics and preoperative baseline characteristics.

\begin{tabular}{|c|c|c|c|c|}
\hline Variables & $\begin{array}{c}\text { All pts } \\
(n=241) \\
\text { Mean } \pm \text { SD } \\
n(\%)\end{array}$ & $\begin{array}{c}\text { Group LT } \\
(n=94) \\
\text { Mean } \pm \text { SD } \\
n(\%)\end{array}$ & $\begin{array}{c}\text { Group HT } \\
(n=147) \\
\text { Mean } \pm \text { SD } \\
n(\%)\end{array}$ & $p$ value $^{*}$ \\
\hline Age, years & $63.2 \pm 11.7$ & $62.1 \pm 10.7$ & $63.9 \pm 12.3$ & 0.152 \\
\hline Gender (male) & $160(66.4)$ & $66(70.2)$ & $94(64.0)$ & 0.331 \\
\hline \multicolumn{5}{|l|}{ Comorbidities } \\
\hline Hypertension & $208(86.3)$ & $79(84.0)$ & $129(87.8)$ & 0.446 \\
\hline Diabetes mellitus & $24(10.0)$ & $8(8.5)$ & $16(10.9)$ & 0.661 \\
\hline Atherosclerosis & $101(41.9)$ & $33(35.1)$ & $68(46.3)$ & 0.108 \\
\hline Marfan syndrome & $12(5.0)$ & $1(1.1)$ & $11(7.5)$ & 0.031 \\
\hline Previous cardiac surgery & $7(2.9)$ & $2(2.1)$ & $5(3.4)$ & 0.708 \\
\hline \multicolumn{5}{|l|}{ Symptoms at admission } \\
\hline Shock & $40(16.6)$ & $13(13.8)$ & $27(18.4)$ & 0.381 \\
\hline Severe or worst-ever pain & $223(92.5)$ & $82(87.2)$ & $141(95.9)$ & 0.021 \\
\hline Chest pain & $202(83.8)$ & $67(71.3)$ & $135(91.8)$ & $<0.001$ \\
\hline Syncope & $37(15.4)$ & $22(23.4)$ & $15(10.2)$ & 0.010 \\
\hline Pulse deficits on presentation & $110(45.6)$ & $33(35.1)$ & $77(52.4)$ & 0.012 \\
\hline
\end{tabular}

* $p$ values refer to Mann-Whitney test for the quantitative data and to Fisher's exact probability test for the categorical data. pts: patients, Group LT: arrest circulation temperature $<24^{\circ} \mathrm{C}$, Group $\mathrm{HT}$ : higher arrest temperature $\geq 24^{\circ} \mathrm{C}$.

TABLE 2: Intraoperative data.

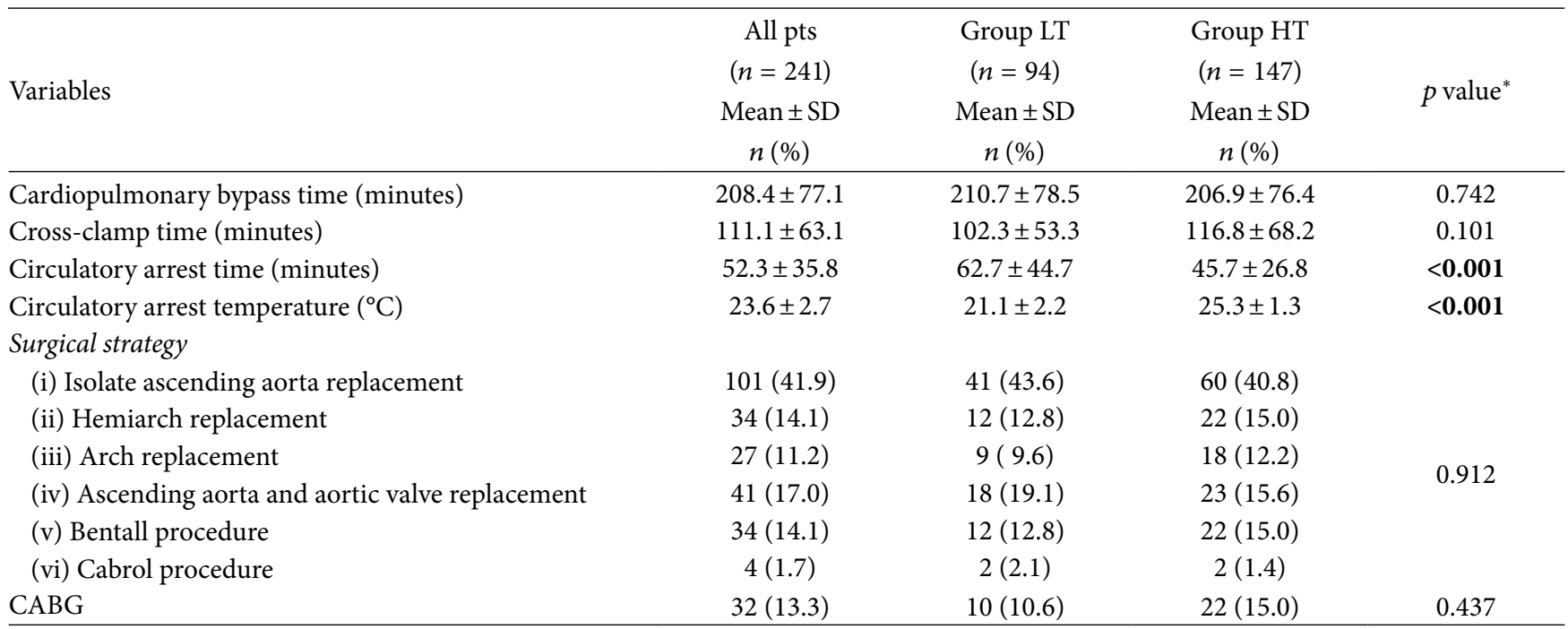

* $P$ values refers to Mann-Whitney test for the quantitative data and to chi square test or Fisher's exact probability test (in case of two-by-two contingency tables) for the categorical data. CABG: Coronary artery bypass graft surgery; pts: patients; Group LT: arrest circulation temperature < $24^{\circ} \mathrm{C}$; Group HT: higher arrest temperature $\geq 24^{\circ} \mathrm{C}$.

Since, no changes occurred in our rewarming protocol, this results may be attributed to the fact that our surgeons have initiated to practice the surgical treatment of type A aortic dissection almost 18 years ago. And therefore, the difference in the HCA time between the 2 groups and the improvement of the results may be explained by the experience and certainly by the learning curve in this field acquired over 16 years.

We found a significant difference in in-hospital mortality, with a significant reduction in Group HT, and a significant reduction of global incidence of complications.
In our study, the incidence of neurologic complications did not differ between the two groups. A possible explanation for this difference may be that we adopted in our procedures the same protection technique (ACP).

Using moderate hypothermia is correlated to a compromise/suppression of visceral organ metabolism. Physiologically, the kidneys are the most sensitive organs to ischemia, followed by the liver and the bowel. In this study, there was no significant difference in the incidence of AKI requiring dialysis, Chronic Kidney Injury. Even though, we found a statistically significant reduction of intestinal ischemia in group HT. In 
TABLE 3: Results.

\begin{tabular}{|c|c|c|c|c|}
\hline Variables & $\begin{array}{c}\text { All pts } \\
(n=241) \\
\text { Mean } \pm \text { SD } \\
n(\%)\end{array}$ & $\begin{array}{c}\text { Group LT } \\
(n=94) \\
\text { Mean } \pm \text { SD } \\
n(\%)\end{array}$ & $\begin{array}{c}\text { Group HT } \\
(n=147) \\
\text { Mean } \pm \text { SD } \\
n(\%)\end{array}$ & $p$ value $^{*}$ \\
\hline Time for intubation (hours) & $114.6 \pm 171.3$ & $144.0 \pm 215.9$ & $96.5 \pm 134.5$ & 0.6532 \\
\hline Drainage output over $24 \mathrm{~h}(\mathrm{ml})$ & $924.1 \pm 703.8$ & $1071.3 \pm 895.9$ & $833.3 \pm 537.4$ & 0.0353 \\
\hline Complication (overall) & $150(62.2)$ & $68(72.3)$ & $82(55.8)$ & 0.010 \\
\hline Limb Ischemia & $22(10.6)$ & $11(13.9)$ & $11(8.6)$ & 0.251 \\
\hline Acute kidney injury & $65(31.4)$ & $24(30.4)$ & $41(32.0)$ & 0.878 \\
\hline Acute kidney injury requiring dialysis & $51(24.6)$ & $23(29.1)$ & $28(21.9)$ & 0.250 \\
\hline Chronic kidney Injury & $19(9.2)$ & $7(8.9)$ & $12(9.4)$ & 1.000 \\
\hline Intestinal Ischemia & $14(6.8)$ & $10(12.7)$ & $4(3.1)$ & 0.011 \\
\hline Neurological deficits & $46(22.2)$ & $20(25.3)$ & $26(20.3)$ & 0.491 \\
\hline Focal deficit & $38(18.4)$ & $14(17.7)$ & $24(18.8)$ & 1.000 \\
\hline Coma & $15(7.3)$ & $7(8.9)$ & $8(6.3)$ & 0.583 \\
\hline Tracheostomy & $41(20.0)$ & $17(21.8)$ & $24(18.9)$ & 0.719 \\
\hline Infections & $73(35.3)$ & $34(43.0)$ & $39(30.5)$ & 0.074 \\
\hline In-hospital stay (days) & $17.3 \pm 15.8$ & $19.0 \pm 18.9$ & $16.1 \pm 13.4$ & 0.3780 \\
\hline 30-day mortality & $64(26.6)$ & $32(34.0)$ & $32(21.8)$ & 0.038 \\
\hline \multicolumn{5}{|l|}{ in-hospital results } \\
\hline (i) Intraoperative death & $34(14.1)$ & $15(16.0)$ & $19(12.9)$ & \multirow{3}{*}{0.019} \\
\hline (ii) Postoperative death & $36(14.9)$ & $21(22.3)$ & $15(10.2)$ & \\
\hline (iii) Alive at discharge & $171(71.0)$ & $58(61.7)$ & $113(76.9)$ & \\
\hline
\end{tabular}

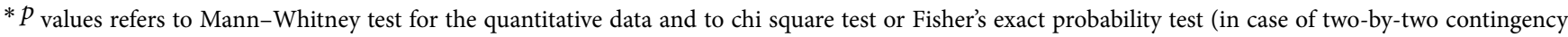
tables) for the categorical data. pts: Patients; Group LT: arrest circulation temperature $<24^{\circ} \mathrm{C}$; Group HT: higher arrest temperature $\geq 24^{\circ} \mathrm{C}$.

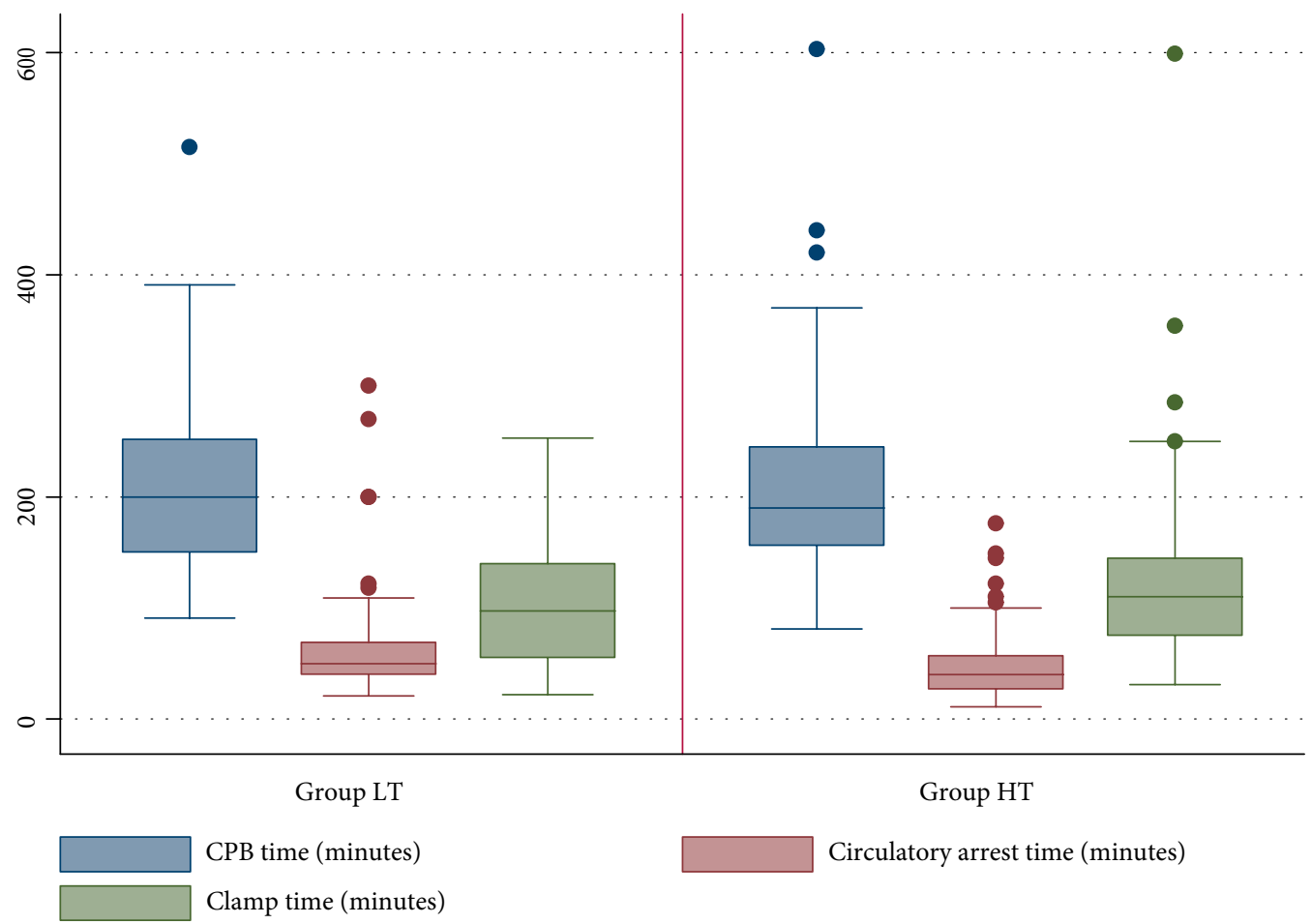

FIGURE 2: Box plot showing distribution of intraoperatory times over our population. Group LT: Arrest circulation temperature $<24^{\circ} \mathrm{C}$; Group HT: higher arrest temperature $\geq 24^{\circ} \mathrm{C}$; $\mathrm{CPB}$ time: Cardiopulmonary bypass time. 
fact, some studies suggest that the $\mathrm{pH}$ decreases and causes intestinal mucosal injury when the intestinal oxygen supply decreases to $50-60 \%$ [16].

In our study, furthermore, we observed a reduction of infections in the group HT, even if not statistically significant. Many factors may explain these results. First of all, the pump itself is associated with a broad array of adverse physiologic sequelae that predispose cardiac surgery patients to infectious complications. Cardiopulmonary bypass is known to compromise humoral immunologic defenses, reduce phagocytosis, and activate white blood cells, all of which impair the ability to neutralize infectious organisms. The length of a surgical procedure is also generally correlated with the risk of postoperative infection [17]. Secondly, the gastrointestinal bacterial population is an estimated at 1014; when the mucosal barrier is destroyed, these bacteria translocate across the intestines into the vasculature, resulting in severe infection and MODS $[18,19]$. In addition, hypoxia disrupts the bacteria themselves, leading to intestinal flora disorder [20].

Finally, it is believed that hypothermia, also, is associated with infections. Possible adverse effects of hypothermia can result from two mechanisms: reduced peripheral blood flow (vasoconstriction) and an impaired immune system. The additional causative factors include higher postoperative protein loss and clotting disturbances, mainly the impaired function of platelets necessary for the initiation of proper healing through platelet plug formation. The above-mentioned disorders may lead to even threefold higher incidence of surgical wound infections and substantially reduced reactivity of the immune system in response to infection.

Since the two groups are similar for type of surgical procedures, we consider these differences depending on the lower temperature reached, according to the current literature. From our analysis, we can consider secure performing aortic surgery in circulatory arrest with a temperature range $\geq 24^{\circ} \mathrm{C}$, with the association of ACP cerebral protection strategy.

\section{Conclusions}

Since we reached a statistical significance on 30-day mortality $(p=0.038)$ and on postoperative death $(p<0.03$, see supplementary materials) between those groups, and we did find a global reduction of complications, we can conclude that circulatory arrest performed at temperatures $\geq 24^{\circ} \mathrm{C}$ with ACP is a safe strategy for aortic surgery for AAD. In particular, since in our analysis we found that group HT mean temperature was of $25.3^{\circ} \mathrm{C}$, we believe that a temperature between 25 and $26^{\circ} \mathrm{C}$ is safe for circulatory arrest during type A AAD.

\section{Data Availability}

Our database used to support the findings of this study are available from the corresponding author upon request. Tables showing the distribution between the 2 groups of the arrest circulation temperature distribution and multiple comparisons regarding the in-hospital results are included within the supplementary information file.

\section{Additional Points}

Study Limitations. The main limitation of the current report is that is a retrospective observational study. Our institution switched to the concept of moderate Hypothermia during selective ACP a decade ago, rising the arrest temperature over time, according to surgeon's preferences. In our database we collected data of 10 surgeons, and we did not have a uniform protocol for this procedure due to modifications in our surgical strategies over the years. On the other hand, in our database intraoperative data like utilization of blood products are missing, therefore searching any correlation between these data and complications was not possible.

\section{Ethical Approval}

Not applicable, accordingly to The National Code on Clinical Trials has declared that ethics approval is not necessary for real retrospective studies.

\section{Consent}

All our patients sign a consent for medical/surgical treatment, privacy terms, future studies and participate in research.

\section{Conflicts of Interest}

The authors deny any conflict of interest.

\section{Authors' Contributions}

(i) Conception and design: Francesco Macrina, MD. (ii) Administrative support: Francesco Macrina, MD, Fabio Miraldi, MD, Luigi Tritapepe, MD. (iii) Provision of study materials or patients: Mizar D’abramo, MD, Wael Saade, MD. (iv) Collection and assembly of data: Mizar D'abramo, MD, Wael Saade, MD. (v) Data analysis: Maria Cristina Acconcia, MD. (vi) Data interpretation: Maria Cristina Acconcia, MD Francesco Macrina, MD, Mizar D’abramo, MD, Wael Saade, MD. (vii) Manuscript writing: All authors. (viii) Final approval of manuscript: All authors.

\section{Funding}

The authors received no specific funding for this work.

\section{Supplementary Materials}

Tables showing the distribution between the 2 groups of the arrest circulation temperature distribution and multiple comparisons regarding the in-hospital results are included within the supplementary information file. (Supplementary Materials) 


\section{References}

[1] T. D. Yan, P. G. Bannon, J. Bavaria et al., "Consensus on hypothermia in aortic arch surgery," Annals of Cardiothoracic Surgery, vol. 2, no. 2, pp. 163-168, 2013.

[2] C. K. Mezrow, P. S. Midulla, A. M. Sadeghi et al., "Evaluation of cerebral metabolism and quantitative electroencephalography after hypothermic circulatory, arrest and low-flow cardiopulmonary bypass at different temperatures," The Journal of Thoracic and Cardiovascular Surgery, vol. 107, no. 4, pp. 1006-1019, 1994.

[3] M. L. James, N. D. Andersen, M. Swaminathan et al., "Predictors of electrocerebral inactivity with deep hypothermia," The Journal of Thoracic and Cardiovascular Surgery, vol. 147, no. 3, pp. 1002-1007, 2014.

[4] R. De Paulis, M. Czerny, L. Weltert et al., "Current trends in cannulation and neuroprotection during surgery of the aortic arch in Europe," European Journal of Cardio-Thoracic Surgery, vol. 47, no. 5, pp. 917-923, 2015.

[5] R. B. Griepp, M. A. Ergin, J. N. McCullough et al., "Use of hypothermic circulatory arrest for cerebral protection during aortic surgery," Journal of Cardiac Surgery, vol. 12, no. 2, pp. 312-321, 1997.

[6] M. A. Ergin, E. B. Griepp, S. L. Lansman, J. D. Galla, M. Levy, and R. B. Griepp, "Hypothermic circulatory arrest and other methods of cerebral protection during operations on the thoracic aorta," Journal of Cardiac Surgery, vol. 9, no. 5, pp. 525-537, 1994.

[7] E. Apostolakis and K. Akinosoglou, "The methodologies of hypothermic circulatory arrest and of antegrade and retrograde cerebral perfusion for aortic arch surgery," Annals of Thoracic and Cardiovascular Surgery, vol. 14, no. 3, pp. 138-148, 2008.

[8] J. E. Bavaria and A. Pochettino, "Retrograde cerebral perfusion (RCP) in aortic arch surgery: efficacy and possible mechanisms of brain protection," Seminars in Thoracic and Cardiovascular Surgery, vol. 9, no. 3, pp. 222-232, 1997.

[9] B. G. Leshnower, V. H. Thourani, M. E. Halkos et al., "Moderate versus deep hypothermia with unilateral selective antegrade cerebral perfusion for acute type A dissection," The Annals of Thoracic Surgery, vol. 100, no. 5, pp. 1563-1569, 2015.

[10] F. J. Wippold, "Imaging, expert panel on neurologic. Focal neurological deficits," AJNR American Journal of Neuroradiology, vol. 29, no. 10, pp. 1998-2000, 2008.

[11] C. Eris, S. Yavuz, S. Yalcinkaya et al., "Acute mesenteric ischemia after cardiac surgery: an analysis of 52 patients," The Scientific World Journal, vol. 2013, pp. 1-8, 2013.

[12] H, W. Walling and F, A. Manian, "Predictive value of leukocytosis and neutrophilia for bloodstream infection," Infectious Diseases in Clinical Practice, vol. 12, no. 1, pp. 2-6, 2004.

[13] S. Kumar, Y. Mehta, M. Vats, R. Chand, P. Kapoor, and N. Trehan, "An observational study to know the association of leukocytosis and fever with infection in post cardiac surgery patients," Indian Heart Journal, vol. 59, no. 4, pp. 316-322, 2007.

[14] D. H. Tian, B. Wan, P. G. Bannon et al., "A meta-analysis of deep hypothermic circulatory arrest versus moderate hypothermic circulatory arrest with selective antegrade cerebral perfusion," Annals of Cardiothoracic Surgery, vol. 2, pp. 148-58, 2013.

[15] P. P. Urbanski, A. Lenos, P. Bougioukakis, I. Neophytou, M. Zacher, and A. Diegeler, "Mild-to-moderate hypothermia in aortic arch surgery using circulatory arrest: a change of paradigm?," European Journal of Cardio-Thoracic Surgery, vol. 41, pp. 185-191, 2012.

[16] G. B. Bulkley, P. R. Kvietys, D. A. Parks, M. A. Perry, and D. Neil Granger, "Relationship of blood flow and oxygen consumption to ischemic injury in the canine small intestine," Gastroenterology, vol. 89, no. 4, pp. 852-857, 1985.

[17] R. Ariano and G. G. Zhanel, "Antimicrobial prophylaxis in coronary bypass surgery: a critical appraisal," DICP: The Annals of Pharmacotherapy, vol. 25, no. 5, pp. 478-484, 1991.

[18] C. L. Leaphart and J. J. Tepas, "The gut is a motor of organ system dysfunction," Surgery, vol. 141, no. 5, pp. 563-569, 2007.

[19] C. L. Leaphart and J. J. Tepas, "The gut is a motor of organ system dysfunction," Surgery, vol. 141, no. 5, pp. 563-569, 2007.

[20] M. G. Espey, "Role of oxygen gradients in shaping redox relationships between the human intestine and its microbiota," Free Radical Biology and Medicine, vol. 55, pp. 130-140, 2013. 